\title{
PROPAGACIÓN IN VITRO Y ACLIMATIZACIÓN DE EUCHILE MARIAE (AMES) WITHNER (ORCHIDACEAE)
}

\author{
IrIS SuÁREZ-QuiJadA ${ }^{1,2}$, Mabel HeRnÁNDEZ-Altamirano, \\ VÍCTOR M. ChÁVEZ-Ávila ${ }^{1,3}$, Estela SANDOVAL-ZAPOTITLA ${ }^{1}$ \\ $\&$ Alejandro Martinez-PAlacios ${ }^{1}$ \\ 'Jardín Botánico, Instituto de Biología, Universidad Nacional Autónoma de México, A.P. 70-614, \\ México D. F. 04510, México. \\ Authors for correspondence: ${ }^{2}$ iris_suarez82@yahoo.com.mx, ${ }^{3}$ victorm@ibiologia.unam.mx
}

\begin{abstract}
Orchid micropropagation of species Euchile mariae was achieved from the in vitro culture of protocorms sections, obtained from the germination of seeds. The top and bottom protocorms sections, used as explants, were cultivated in modified MS culture medium, added with different concentrations of $\alpha$-naphthaleneacetic acid (NAA) and 6-benzylaminopurine (BA). The morphogenetic response obtained of both types of explants, was the formation of protocorm like bodies (PLB's), that gave place to the formation of new plantlets. Of two tested explants the biggest formation of PLB's was obtained from the bottom protocorms sections. The acclimatization of the plantlets was successful, with a $100 \%$ percent survival. Plant cell tissue culture represents a useful alternative for the study, conservation and massive propagation of this and other endangered species.
\end{abstract}

PALABRAS ClAVE: micropropagación, orquídeas, Euchile, PLB's, aclimatización, conservación ex situ

\section{Introducción}

México es un país megadiverso, se estima que alberga más del $12 \%$ de la biota del planeta (Mittermeier 1988, Toledo 1994), ocupando el cuarto lugar en diversidad vegetal a nivel mundial (Magaña \& Villaseñor 2002), resultado de la combinación de distintos factores como su historia geológica, posición geográfica, diversidad de altitudes, climas y orografía que presenta (Ramamoorthy et al. 1993). Aunado a estos factores presenta una gran cantidad de endemismos; se estima que entre el $10 \%$ y $15 \%$ de los géneros y $54.2 \%$ de las especies de plantas vasculares de México son endémicas (Magaña \& Villaseñor 2002), siendo las Orchidaceae una de las familias de plantas con mayor número de especies endémicas. De las 20, 000 a 30, 000 especies de orquídeas que se reportan a nivel mundial (Dressler 1981, Arditti 1992, Dressler 1993, Espejo et al. 2002, Hágsater et al. 2005), México cuenta con aproximadamente 1106 especies y subespecies mexicanas descritas, distribuidas en 159 géneros, de las cuales el $40 \%$ son endémicas, es decir, aproximadamente 444 especies (Soto 1996). Un dato más reciente sugiere que se distribuyen cerca de 1300 especies, agrupadas en 170 géneros (Soto \& Salazar 2004). Desafortunadamente, México presenta graves problemas ambientales y sociales que ponen en peligro parte importante de su biodiversidad (Hágsater et al. 2005); de manera que la orquideoflora mexicana se encuentra seriamente amenazada, principalmente por actividades humanas, tales como la deforestación, erosión de suelos, reducción y fragmentación de hábitats y la extracción ilegal de especies (UICN /SSC Orchid Specialist Group 1996). Esto demuestra que es urgente e indispensable establecer estrategias de conservación para esta familia de plantas.

Euchile mariae (Ames) Withner, es una orquídea epífita y endémica de México que se distribuye en los estados de Tamaulipas, San Luis Potosí, Hidalgo, Guanajuato, Querétaro, Puebla y Veracruz. Habita en bosques de encino, pino-encino y liquidámbar, a una altitud de 800 a 1350 metros sobre el nivel del mar (Soto 2002). Se encuentran catalogada por la Norma Oficial Mexicana (NOM-059-ECOL-2001) como una especie amenazada (SEMARNAT 2002), esto debido principalmente a la destrucción de su hábitat y al saqueo y comercio ilegal de plantas silvestres. Así mismo, al igual que muchas otras especies de 
orquídeas es una especie de lento crecimiento y largo ciclo de vida por lo que existe escaso reclutamiento de nuevos individuos en condiciones naturales (Ávila \& Oyama 2002). En este sentido, el Cultivo de Tejidos Vegetales proporciona una excelente herramienta para el estudio, propagación y conservación de estas especies. El presente estudio describe un protocolo para la micropropagación de Euchile mariae mediante el cultivo de secciones de protocormos y el efecto de los reguladores de crecimiento ANA y BA para inducir una respuesta morfogenética a partir de estos explantes.

\section{Materiales y Métodos}

Se utilizó una cápsula de Euchile mariae antes de su dehiscencia, ésta se colocó en una solución de hipoclorito de sodio al $30 \%(\mathrm{v} / \mathrm{v})$, durante 30 minutos en agitación constante, seguido de tres enjuagues con agua destilada estéril dentro de la campana de flujo laminar, en donde se colocó sobre una caja petri estéril y se disectó con ayuda de pinzas y bisturí. Con una espátula se tomaron las semillas de la cápsula y se sembraron en frascos de $125 \mathrm{ml}$ de capacidad conteniendo $25 \mathrm{ml}$ de medio MS modificado (Murashige \& Skoog 1962).

El pH del medio de cultivo se ajustó a 5.5 con soluciones de $\mathrm{NaOH}$ y de $\mathrm{HCl}$ a $0.1,0.5$ y $1 \mathrm{~N}$, antes de agregar $4 \mathrm{~g} / 1$ de gelrite. Los frascos con el medio de cultivo fueron esterilizados en un autoclave a $121^{\circ} \mathrm{C}$ y $1.5 \mathrm{~kg} / \mathrm{cm}^{2}$ durante 15 minutos. Todos los cultivos fueron incubados a $25 \pm 1^{\circ} \mathrm{C}$, con un fotoperiodo de $16 \mathrm{~h}$ luz y $8 \mathrm{~h}$ de obscuridad y $50 \mu \mathrm{Mol} / \mathrm{m} / \mathrm{s}$ de intensidad luminosa.

Los explantes utilizados para iniciar los ensayos de inducción fueron mitades de protocormos cuando éstos tenían un tamaño promedio de $2-5 \mathrm{~mm}$ de longitud y presentaban el primer primordio foliar. En condiciones de asepsia, los protocormos se colocaron sobre una caja Petri estéril, en donde fueron disectados transversalmente con ayuda de pinzas de disección y bisturí, obteniéndose así secciones apicales y basales de protocormos. Ambas secciones de protocormos fueron sembradas en medio MS modificado, en presencia de distintas concentraciones de ácido anaftalenacético (ANA) $(0,0.1,0.5,1 \mathrm{mg} / \mathrm{l})$ y benciladenina (BA) $(0,1,2$ y $3 \mathrm{mg} / \mathrm{l})$.
Con un microscopio estereoscópico se cuantificó el número de PLB's formados por explante para cada tratamiento. Los datos obtenidos fueron sometidos a un análisis de varianza de una vía (ANOVA) y se aplicó un análisis de Tukey y Kramer (SAS 2000) para determinar las diferencias de medias estadísticamente significativas entre tratamientos. Después de 165 días de cultivo, los PLB's obtenidos fueron individualizados y subcultivados en el mismo medio MS modificado pero sin reguladores de crecimiento con el fin de incrementar su talla hasta formar plantas completas. Las plantas obtenidas fueron colocadas en troncos de encino y tepozán para su aclimatización. Sobre las raíces se agregó una pequeña cantidad de Sphagnum y agrolita (proporción 3:1) y a su vez sobre éste fue colocada una porción de gasa adhiriéndola a los troncos con hilo de cáñamo.

\section{Resultados y Discusión}

La germinación de las semillas se registró a los 15 días después de realizada su siembra en el medio MS modificado y fue mayor al $90 \%$. El porcentaje de germinación obtenido para Euchile mariae, es similar al reportado para diferentes géneros de orquídeas utilizando frutos aún no dehiscentes (George \& Sherrington 1984). Hernández et al. (2001), reportan la germinación de semillas de Laelia anceps y Catasetum intergerrinum cercana al $100 \%$ en medio Knudson $\mathrm{C}$ a partir de cápsulas indehiscentes. En nuestros cultivos, se observó una hidratación de las semillas y ruptura de la testa seminal dando lugar a la formación de protocormos, en los que después de 30 días de cultivo se formaron hacia el ápice los primeros primordios foliares. Los protocormos obtenidos en esta etapa de desarrollo al ser seccionados en mitades apicales y basales y cultivados en medio MS modificado adicionado con distintas concentraciones de ácido $\alpha$-naftalenácetico (ANA) y benciladenina (BA), presentaron una apariencia nodular que se hizo evidente a partir de los 30 días de cultivo (Fig. 1A). A los 65 días de cultivo los nódulos formados mostraron un cambio en su tamaño y morfología, éstos comenzaron a adquirir una forma redondeada semejante a la de un protocormo, denominándose a las estructuras formadas cuerpos parecidos a protocormos o protocorm like bodies (PLB's) que surgieron de manera 


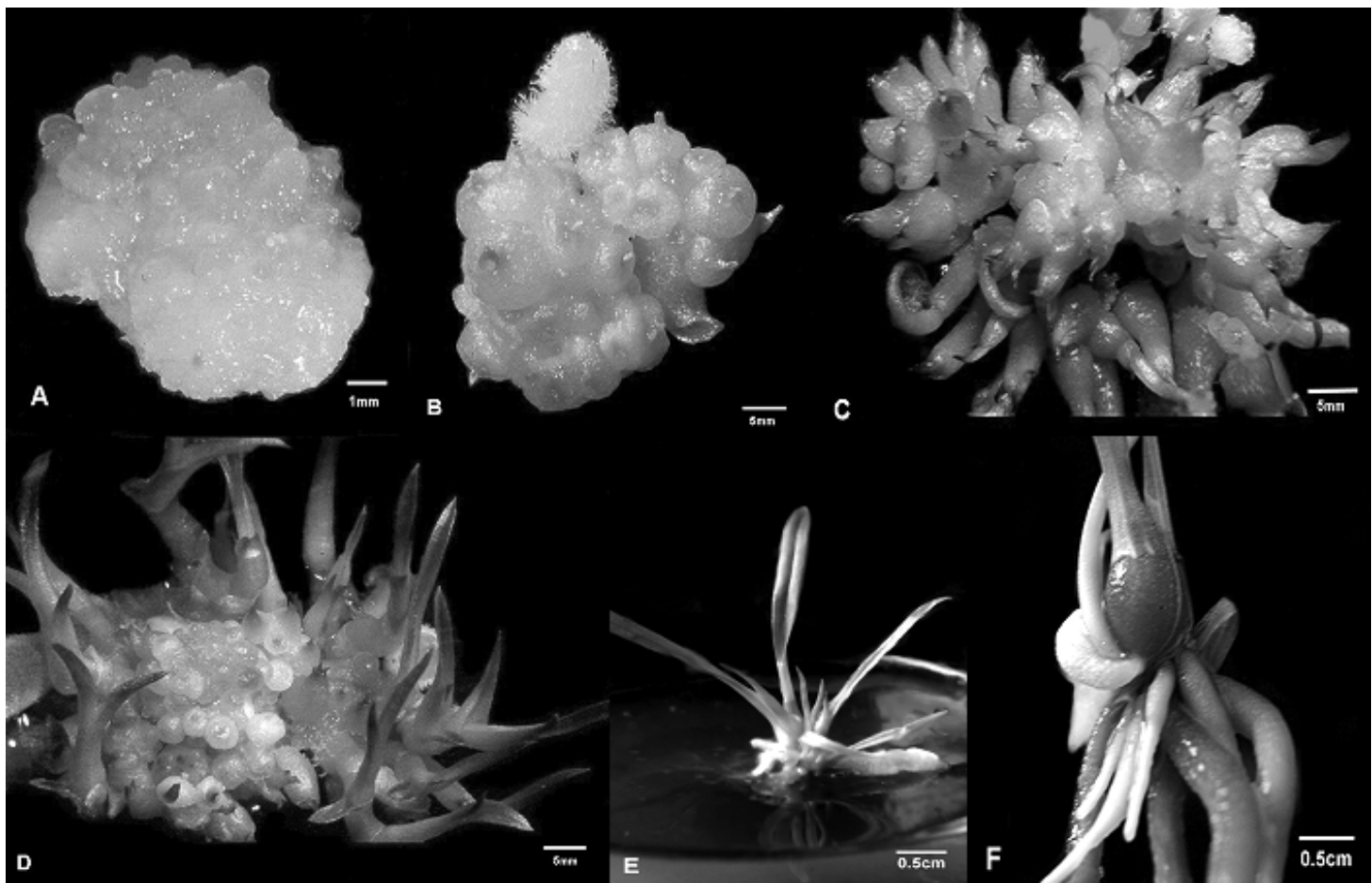

FIGURA 1. Formación de PLB's y desarrollo de plántulas de Euchile mariae a partir del cultivo in vitro de secciones apicales y basales de protocormos en medio MS modificado. A) Desarrollo de nódulos en la superficie del explante a los 30 días. B) Formación directa de PLB's a partir del explante, a los 65 días. C) Elongación de los PLB's, a los 120 días. D) Desarrollo foliar y radicular, a los 165 días. Fotografías tomadas por Isabel Pineda Hernández.

directa del explante (Fig. 1B). A los 120 días de cultivo era notoria la elongación que estaba iniciando en los PLB's formados (Fig. 1C). A los los 165 días los PLB's presentaban hojas más desarrolladas y comenzó la aparición de la primer raíz (Fig. 1D).

La inducción de una respuesta morfogenética en Euchile mariae, a partir del cultivo de mitades de protocormos (apicales y basales) en medio MS modificado, fue diferencial respecto al número de PLB's formados. La mayor formación de PLB's se registró a partir de las secciones basales de protocormos, en donde al termino del periodo de inducción (165 días de cultivo) se obtuvieron un promedio de $11.44 \pm$ 9.64 PLB's por explante, mientras que para las secciones apicales se formaron en promedio $4.98 \pm 5.33$ PLB's por explante. Al cultivar las secciones apicales de protocormos, la mejor respuesta morfogenética se obtuvo en el medio MS modificado adicionado con 1 $\mathrm{mg} / \mathrm{l}$ de ambos reguladores de crecimiento, donde se formó el mayor número de PLB's por explante (11.00 \pm 9.55 ) (Tabla 1).
Resultados similares fueron observados en el cultivo in vitro de mitades de protocormos de Laelia anceps donde obtuvieron la mayor formación de brotes por explante en cultivos en medio Knudson $\mathrm{C}$ adicionado con $0.5 \mathrm{mg} / 1 \mathrm{de}$ BA y con $1 \mathrm{mg} / 1$ de ANA (Hernández et al. 2001). Así mismo, Mauro et al. (1994), sugieren utilizar altas concentraciones de BA y bajas concentraciones de ANA para lograr la formación de un gran número de brotes y PLB's en Cattleya aurantiaca en medio MS, encontrando la máxima formación de PLB's utilizando $10 \mathrm{mg} / \mathrm{l}$ de BA en combinación con $0.1 \mathrm{mg} / 1$ de ANA.

En el caso de las secciones basales de protocormos, el mayor número de PLB's se formó en el medio MS modificado adicionado con $1 \mathrm{mg} / 1$ de BA, sin la adición de ANA, obteniéndose un promedio de $33.07 \pm$ 20.75 PLB's por explante (Tabla 2). Nuestros resultados coinciden con los reportados por Baltazar (2004), quien al cultivar mitades de protocormos de Oncidium tigrinum, encontró que el mejor tratamiento para la formación de PLB's y su desarrollo a plán- 
TABLA 1. Promedio de PLB's por explante obtenidos a los 165 días de cultivo, a partir de secciones apicales de protocormos de Euchile mariae, en medio MS modificado adicionado con distintas concentraciones de ANA y BA.

\begin{tabular}{|c|c|c|}
\hline $\begin{array}{c}\text { Tratamiento } \\
\text { hormonal } \\
\text { ANA/BA (mg/l) }\end{array}$ & $N^{\circ}$ total de PLB's & $\begin{array}{l}\text { Promedio de PLB's } \\
\text { por explante } \pm \text { D.S }\end{array}$ \\
\hline $1 / 1$ & 440 & $11.00 \pm 9.55^{\mathrm{a}}$ \\
\hline $0 / 3$ & 388 & $9.70 \pm 8.06^{\mathrm{a}}$ \\
\hline $0.1 / 3$ & 385 & $9.62 \pm 11.79^{a}$ \\
\hline $1 / 3$ & 348 & $8.70 \pm 9.07 \mathrm{ab}$ \\
\hline $0 / 1$ & 199 & $4.97 \pm 5.31^{\mathrm{bc}}$ \\
\hline $0 / 0$ & 183 & $4.57 \pm 4.34 \mathrm{bc}$ \\
\hline $0.5 / 3$ & 176 & $4.40 \pm 6.18 \mathrm{bc}$ \\
\hline $0 / 2$ & 149 & $3.72 \pm 4.46^{\mathrm{c}}$ \\
\hline $0.1 / 1$ & 145 & $3.62 \pm 3.29^{\mathrm{c}}$ \\
\hline $0.5 / 1$ & 127 & $3.17 \pm 4.57^{\mathrm{c}}$ \\
\hline $0.1 / 2$ & 123 & $3.07 \pm 2.67^{\mathrm{c}}$ \\
\hline $1 / 2$ & 100 & $2.85 \pm 2.86^{\mathrm{c}}$ \\
\hline $0.5 / 2$ & 113 & $2.82 \pm 3.67^{\mathrm{c}}$ \\
\hline $0.1 / 0$ & 102 & $2.55 \pm 3.78^{c}$ \\
\hline $0.5 / 0$ & 101 & $2.52 \pm 2.91 \mathrm{c}$ \\
\hline $1 / 0$ & 98 & $2.45 \pm 2.69 \mathrm{c}$ \\
\hline
\end{tabular}

( $\mathrm{p} \leq$ 0.0001). D. S.= Desviación estándar, PLB's $=$ Cuerpos parecidos a protocormos.

tulas, fue el que presentaba solamente $1 \mathrm{mg} / \mathrm{l}$ de BA, obteniéndose a su vez en éste el porcentaje más elevado de sobrevivencia para los explantes.

La función del ANA al parecer no jugó un papel preponderante en la formación de PLB's, mientras que la adición de BA al medio de cultivo favorece la formación de éstos tanto en las secciones apicales como basales de los protocormos. Taiz (1998), establece que la aplicación directa de citocininas al medio de cultivo estimula el crecimiento de yemas laterales en muchas especies, anulando el efecto inhibidor del meristemo apical de brote.

Una vez concluida la etapa de inducción, después de 165 días de cultivo, los PLB's obtenidos a partir de las secciones apicales y basales de protocormos de Euchile mariae, al ser individualizados y subcultiva-
TABLA 2. Promedio de PLB's por explante obtenidos a los 165 días, a partir de secciones basales de protocormos de Euchile mariae, en medio MS modificado adicionado con distintas concentraciones de ANA y BA.

\begin{tabular}{|c|c|c|}
\hline $\begin{array}{c}\text { Tratamiento } \\
\text { hormonal } \\
\text { ANA/BA (mg/l) }\end{array}$ & $N^{\circ}$ total de PLB's & $\begin{array}{l}\text { Promedio de PLB's } \\
\text { por explante } \pm \text { D.S }\end{array}$ \\
\hline $0 / 1$ & 1323 & $33.07 \pm 20.75^{a}$ \\
\hline $0 / 0$ & 954 & $23.85 \pm 16.25^{b}$ \\
\hline $0.5 / 3$ & 853 & $21.32 \pm 15.61^{b}$ \\
\hline $0 / 3$ & 823 & $20.57 \pm 11.89^{b}$ \\
\hline $0.1 / 1$ & 452 & $11.30 \pm 9.75^{\mathrm{c}}$ \\
\hline $0.1 / 3$ & 435 & $10.87 \pm 8.58^{\mathrm{c}}$ \\
\hline $0 / 2$ & 393 & $9.82 \pm 11.08^{c}$ \\
\hline $0.1 / 0$ & 317 & $7.92 \pm 5.56^{\mathrm{c}}$ \\
\hline $0.5 / 2$ & 309 & $7.72 \pm 8.24^{c}$ \\
\hline $1 / 0$ & 296 & $7.40 \pm 8.12^{c}$ \\
\hline $0.1 / 2$ & 282 & $7.05 \pm 6.79^{c}$ \\
\hline $1 / 1$ & 232 & $5.80 \pm 8.48^{c}$ \\
\hline $0.5 / 1$ & 224 & $5.60 \pm 8.92^{c}$ \\
\hline $0.5 / 0$ & 155 & $3.87 \pm 4.47^{\mathrm{c}}$ \\
\hline $1 / 3$ & 140 & $3.50 \pm 5.20^{\mathrm{c}}$ \\
\hline $1 / 2$ & 122 & $3.48 \pm 4.57^{\mathrm{c}}$ \\
\hline
\end{tabular}

$(\mathrm{p} \leq 0.0001)$. D. S. = Desviación estándar. PLB's $=$ Cuerpos parecidos a protocormos.

dos en medio MS modificado sin reguladores de crecimiento, después de 60 días se desarrollaron hacia la formación de plántulas completas (Fig. 1E). A los 90 días, hacia la base del tallo se observó un ensanchamiento, que correspondió a la formación del pseudobulbo (Fig. 1F).

Las plantas obtenidas a partir del cultivo de ambas secciones de protocormos (Fig. 2A), fueron establecidas en condiciones ex vitro exitosamente en troncos de encino y tepozán (Fig. 2B), obteniéndose en ambos casos un porcentaje de sobrevivencia del $100 \%$ (Fig. 2C).

Los resultados obtenidos en este trabajo ofrecen una alternativa viable y de gran utilidad para la micropropagación de Euchile mariae, como una herramienta que permita reducir la presión que se 


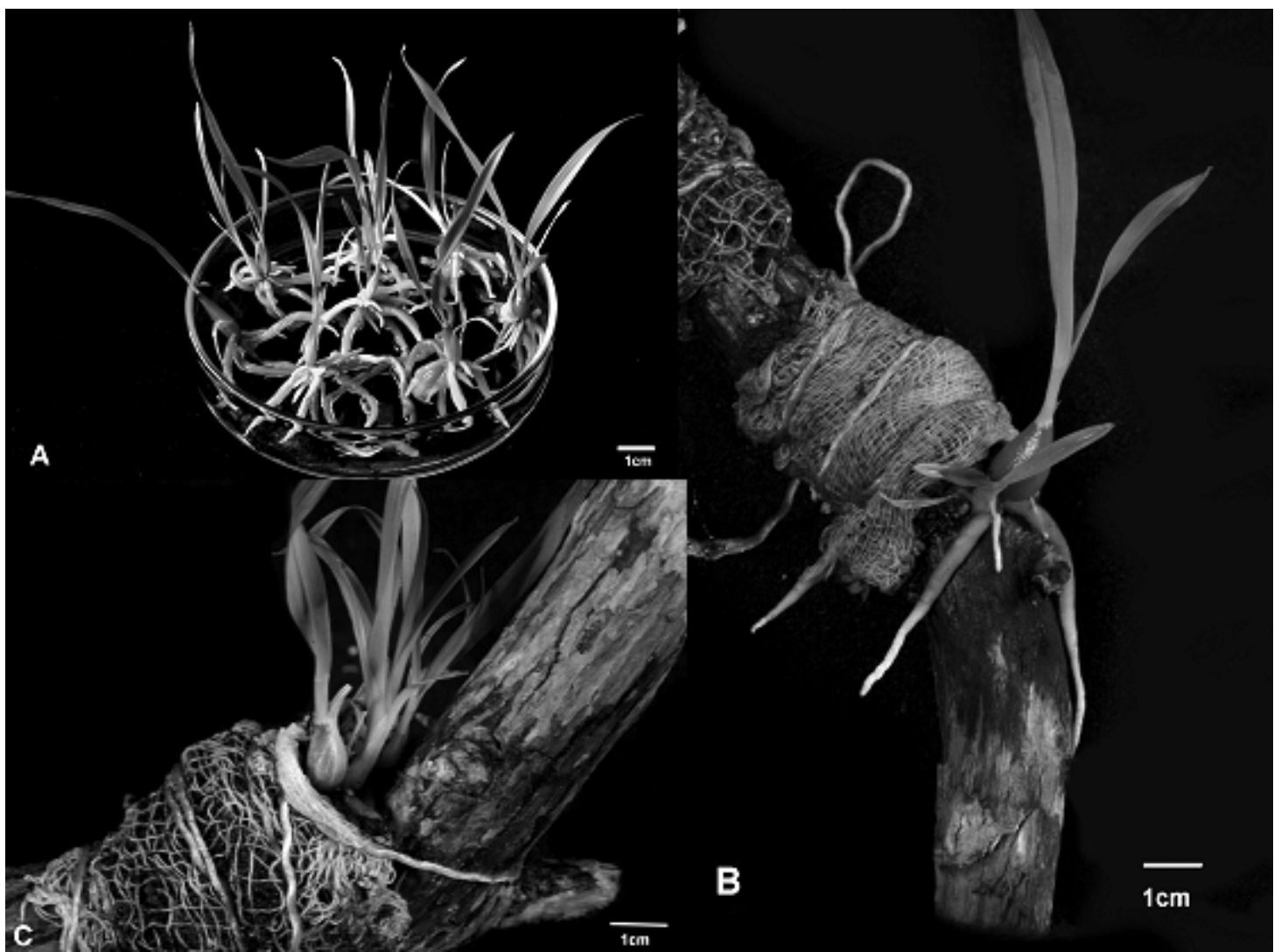

FIgURA 2. Establecimiento ex vitro de las plantas micropropagadas. A) plantas obtenidas a partir de mitades apicales y basales de protocormos de Euchile mariae. B) Montaje de las plantas micropropagadas sobre troncos de tepozán. C) Plantas de E. mariae después de 35 días en condiciones ex vitro. Fotografías tomadas por Mónica Vázquez Cortés.

ejerce en sus poblaciones silvestres y que a su vez, sirva como modelo para la propagación masiva de otras especies de orquídeas, que se encuentren amenazadas y/o en vías de extinción, contribuyendo a su conservación y aprovechamiento sustentable.

Agradecimientos. A Isabel Pineda Hernández y Mónica Vázquez Cortés por la toma de las fotografías para esta investigación. A la Biól Bárbara Estrada Galván por su apoyo técnico

\section{LITERATURA CITADA}

Arditti J. 1992. Fundamentals of orchid biology. John Wiley \& Sons, Inc. USA. 691 p.

Ávila D.I. \& K. Oyama. 2002.Manejo sustentable de Laelia speciosa (Orchidaceae). Biodiversitas 7 (43): 9-12.

Baltazar G.R. 2004. Micropropagación de Oncidium tigrinum Llave \& Lex. (Orchidaceae) a partir de protocormos. Tesis de licenciatura. Facultad de Biología. Universidad Veracruzana. Xalapa, Veracruz. 124 p.

Dressler R.L. 1981. The orchids. Natural history and classi- fication. Harvard University Press. London. 332 p.

Dressler R.L. 1993. Phylogeny and classification of the orchid family. Dioscorides Press. Portland, Oregon. 313 p. Espejo S.A., C.J. García, F.A.R. López, M.R. Jiménez \& S.L. Sánchez. 2002. Orquídeas del estado de Morelos. Orq. (Méx.) Vol. 16. Número único. 332 p.

George E.F. \& P.D. Sherrington.1984. Plant propagation by tissue culture. Handbook and directory of commercial laboratories. Exegetics Ltd. Eversley, Basingstone, England. 709 p.

Hágsater E., M.A. Soto-Arenas, G.A. Salazar-Chávez, R. Jiménez-Machorro, M.A. López-Rosas \& R.L. Dressler. 2005. Las orquídeas de México. Instituto Chinoín. México. 304 p.

Hernández H.J., S.O. Hernández \& R.M. Mata. 2001. Regeneración de plántulas a partir del cultivo in vitro de mitades de protocormos de Laelia anceps Lindl. y Catasetum intergerrimum Hook. Amaranto 14 (1) : 3-12.

Knudson L. 1946. A new nutrient solution for the germination of orchid seeds. Am. Orchid Soc. Bull. 15 : 214-217. Magaña P. \& J.L. Villaseñor. 2002. La flora de México. 
¿Se podrá conocer totalmente? Ciencias 66 : 24-26.

Mauro M., D. Sabapathi \& R.A. Smith. 1994. Influence of benzylaminopurine and alpha naphthalenacetic acid on multiplication and biomass production of Cattleya aurantiaca shoot explants. Lindleyana 9 (3) : 169173.

Mittermeier R.A. 1988. Primate diversity and the tropical forest. Case studies from Brazil and Madagascar and the importance of the megadiversity countries. Pp. 145-154 in: E.O. Wilson (ed.). Biodiversity. National Academy Press. Washington, D. C.

Murashige T. \& F. Skoog. 1962. A revised medium for rapid growth and bioassays with tobacco tissue cultures. Physiol. Plant. 15 : 473-497.

Ramamoorthy T.P., R.Bye, A. Lot \& J.Fa.1993. Biological diversity of Mexico: origins and distribution. Oxford University Press. New York. 812 p.

SEMARNAT. 2002. Norma Oficial Mexicana NOM-059ECOL-2001. Protección ambiental-especies nativas de México de flora y fauna silvestres-categorías de riesgo y especificaciones para su inclusión, exclusión o cambiolista de especies en riesgo. Diario oficial (6 de marzo 2002). México, D.F.
Soto A., M.A. 1996. México. Pp. 53-58 in: IUCN/SSC Orchid specialist group. Orchids-status survey and conservation action plan. IUCN, Gland Switzerland and Cambridge, UK.

Soto A., M.A. 2002. Euchile mariae (Ames) Withner. In: E. Hágsater \& M. Soto (ed.), Icones Orchidacearum. Orchids of Mexico Part 2,3. Asociación Mexicana de Orquideología. A.C. Mexico. Lámina 584.

Soto A., M.A. \& G.A. Salazar. 2004. Orquídeas. Pp. 271295 in: A.J. García-Mendoza, M.J. Ordóñez \& M. Briones-Salas (eds.). Biodiversidad de Oaxaca. Instituto de Biología, UNAM-Fondo Oaxaqueño para la Conservación de la Naturaleza-World Wildlife Fund. México.

Taiz L. \& E. Zeiger. 1998. Plant physiology. Second edition. Sinauer Associates, Inc., Publishers. Sunderland Massachusetts. 690 p.

Toledo V.M. 1994. La diversidad biológica de México. Nuevos retos para la investigación en los noventas. Ciencias. 34: 43-59.

UICN/SSC Orchid Specialist Group. 1996. Orchids-status survey and action plan. IUCN, Gland Switzerland and Cambridge, UK. 153 p.

Iris Suárez Quijada es bióloga egresada de la Universidad Nacional Autónoma de México, dedicada al estudio, conservación y propagación in vitro de especies de orquídeas endémicas de México que se encuentran catalogadas en peligro de extinción. Sigue ligada a los programas de conservación del Jardín Botánico, del Instituto de Biología, de la UNAM. Continúa sus estudios de maestría en el Instituto de Geología de la UNAM, enfocándose al cultivo simbiótico y reintroducción de orquídeas terrestres de la Reserva Ecológica del Pedregal de San Ángel, en la Ciudad de México. 